\title{
Propriedades físicas e mecânicas do colmo inteiro do bambu da espécie Guadua angustifolia
}

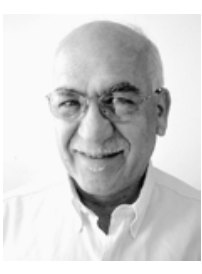

Khosrow Ghavami ${ }^{1} \&$ Albanise B. Marinho²

\begin{abstract}
1 PUC-Rio, Departamento de Engenharia Civil; Rua Marquês de São Vicente 225, Gávea, CEP 22543-900, Rio de Janeiro, RJ, Brasil. E-mail: ghavami@civ.puc-rio.br, Fone (021) 3114-1188, Fax: (021) 3114-1195 (Foto)

2 FAPERJ, PUC-Rio, Departamento de Engenharia Civil. E-mail: abmtenc@civ.puc-rio.br
\end{abstract}

Protocolo $180-27 / 11 / 2002$ - Aprovado em 2/4/2004

\begin{abstract}
Resumo: Este trabalho apresenta os resultados de recentes pesquisas sobre o bambu da espécie Guadua angustifolia, realizadas na Pontifícia Universidade Católica do Rio de Janeiro (PUC-Rio), no qual foram determinadas as propriedades físicas, mecânicas e meso-estruturais dos colmos inteiros. O principal objetivo deste estudo é apresentar, aos profissionais, a possibilidade de usarem o bambu como elemento estrutural. Os resultados apresentados permitirão aos engenheiros e arquitetos selecionar, em seus projetos, as dimensões requeridas, como diâmetro, espessura e distância internodal, tensões de flexão, tensões máximas de tração, compressão e cisalhamento. Estão apresentadas a variação da fração volumétrica ao longo da espessura do bambu e suas propriedades mecânicas ao longo do comprimento total do colmo estudado.
\end{abstract}

Palavras-chave: propriedades mecânicas, propriedades físicas, Guadua angustifolia

\section{Physical and mechanical properties of the whole culm of bamboo of the Guadua angustifolia species}

\begin{abstract}
This work presents recent research results concerning the bamboo Guadua angustifolia carried out at the Pontificia Universidade Catolica, Rio de Janeiro, in which the physical, mechanical and meso-structural properties of the whole bamboo culms were determined. The main objective of this study is to make it possible for professionals to use bamboo more frequently as a structural element. The obtained results allow the engineers and architects to choose for their projects the required dimensions such as diameter, thickness and internodal distance, bending stresses, maximum tensile, compression and shearing stresses. The changing of the volumetric fraction along the bamboo thickness and their mechanical properties along the total length of the studied bamboo culms are presented.
\end{abstract}

Key words: mechanical properties, physical properties, Guadua angustifolia

\section{INTRODUÇÃO}

Em períodos remotos da história, os materiais empregados em elementos mecânicos e estruturais variavam entre diferentes regiões, uma vez que sua utilização dependia da disponibilidade local e a escolha era ainda influenciada por aspectos culturais e estéticos. Os materiais eram processados de maneira rudimentar ou utilizados em estado bruto, sempre envolvendo trabalho intenso com participação de membros da comunidade. De modo geral, observa-se que, em algumas regiões, era intensa a utilização de materiais localmente disponíveis como pedra, aglomerantes naturais, madeira, terra crua, algodão, fibras naturais, fibras de coco, palha de trigo, casca de arroz etc.

Com a industrialização dos produtos e a concentração das populações em grandes centros urbanos, os materiais tradicionais foram gradualmente substituídos por materiais industrializados (também chamados convencionais), tais como o cimento Portland e o aço. Desde os anos 70 estão sendo desenvolvidos materiais avançados, constituídos de polímeros sintéticos, como Rayon, Nylon, Polyester e Aramida, usados como reforço em compósitos, os quais, nos países industrializados, estão gradualmente substituindo o aço e o concreto.

No entanto, os materiais industrializados mobilizam vastos recursos financeiros, consomem enorme quantidade de energia e requerem um processo centralizado. Em conseqüência disto, além de outros efeitos ocorrem, também, problemas de desemprego e habitacionais em áreas rurais e em pequenas cidades, onde os materiais não renováveis são inaproveitados, causando permanente poluição. Neste sentido, torna-se evidente que os materiais ecológicos satisfazem algumas exigências fundamentais para o futuro da humanidade, tais 
como: minimização do consumo de energia, conservação dos recursos naturais, redução da poluição e manutenção de um ambiente saudável (Ghavami, 2001). Assim, os países europeus também já iniciaram pesquisas científicas e sistemáticas sobre esses materiais ecológicos, não poluentes, como fibras vegetais, bambu, resíduos industriais, minerais e agrícolas, que estão sendo estudados sob todos os aspectos do comportamento mecânico. O uso de bambu, resíduos agrícolas, minerais e industriais, tem sido investigados, desde 1979, na PUC-Rio, de forma que sejam, futuramente, uma alternativa como material de construção (Ghavami, 1984, 1992; Ghavami \& Culzoni, 1987).

Para o uso do bambu em grande escala como material de engenharia economicamente viável e com possibilidade de industrialização, faz-se necessário um estudo científico sistemático, através dos processos de plantação, colheita, cura, tratamento e pós-tratamento, além de uma completa análise estatística das propriedades físicas e mecânicas do colmo do bambu inteiro. A partir desses estudos, será possível estabelecer critérios confiáveis de dimensionamento e de emprego de processos industriais viabilizando economicamente o uso do bambu em grande escala.

A estrutura externa do bambu é formada pelos sistemas subterrâneo de rizomas, colmos, galhos e folhas. A planta pode apresentar flores ou frutos, por vez, ou dois, simultaneamente. Os colmos são formados por uma série alternada de nós e entrenós. Com o crescimento do bambu, cada novo nó interno é envolvido por uma folha caulinar protetora (bainha). Os colmos são formados por fibras, vasos e condutores de seiva, que estão desuniformemente distribuídos na seção transversal, envolvidos por uma espécie de matriz denominada parênquima. Esses colmos diferem, segundo a espécie, em comprimento, espessura da parede, diâmetro, espaçamento dos nós e resistência. Em sua maioria são ocos, podendo-se encontrar algumas espécies com entrenós sólidos e outros com água no seu interior.

Liese (1980) afirmou que, do ponto de vista anatômico, o bambu é, de modo geral, constituído por fibras (40\%), células parenquimosas $(50 \%)$ e vasos $(10 \%)$; assim, de acordo com Ghavami \& Rodrigues (2000), a estrutura dos bambus pode ser encarada como sendo um material compósito constituído, a grosso modo, de fibras longas e alinhadas de celulose imersas em uma matriz de lignina. As fibras se concentram mais a medida em que se consideram pontos na espessura cada vez mais próximos da casca, de forma que o material possa resistir às cargas de vento, que são as solicitações mais constantes durante a vida do material na natureza. A Figura 1 mostra a variação da fração volumétrica das fibras na espessura do colmo do bambu Guadua angustifolia em estudo na PUC-Rio.

Os conjuntos vasculares integram os tecidos de condução da seiva e as fibras, que apresentam resistência mecânica que, por sua vez, são "imersas” em uma matriz de lignina (parênquima). Os vasos têm, como função, o transporte de nutrientes da raiz às demais partes da planta e, como os colmos de bambu são bastante esbeltos, os vasos são reforçados por um tecido (esclerênquima) que lhes dá resistência. O conjunto vascular é o componente estrutural mais variado do colmo do bambu; sua forma, tamanho e distribuição, variam no internó e

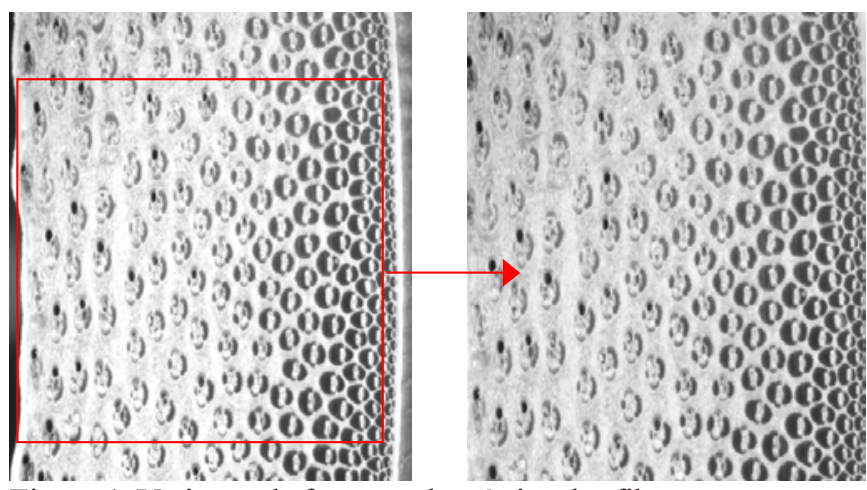

Figura 1. Variação da fração volumétrica das fibras na espessura do colmo do bambu Guadua angustifolia

ao longo do comprimento (altura) do colmo. A base do colmo apresenta uma estrutura completamente diferente quando comparada com a parte central e topo do colmo (Liese, 1998). A Figura 2 mostra imagens dos conjuntos vasculares dos bambus adquiridas num microscópio eletrônico de varredura (MEV), obtidas por Liese (1980).
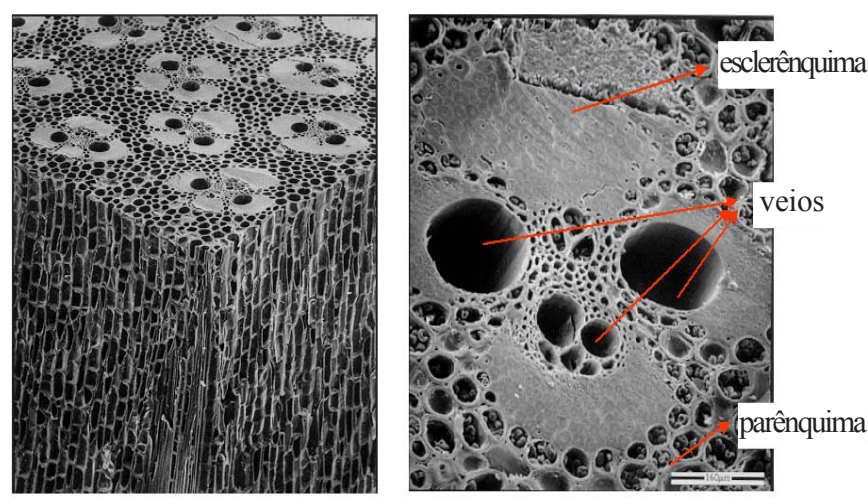

Figura 2. Detalhe dos conjuntos vasculares do bambu

A estrutura fibrosa do bambu, em feixes, se presta exatamente para esforços de tração axial, porém, quando solicitado axialmente, em virtude das fibras estarem imersas em uma matriz de lignina, o que ocorre é uma ruptura por cisalhamento (Culzoni, 1986). Uma outra causa para este fato, reside nas tortuosidades dos feixes e nas mudanças de seções, geralmente nos nós, onde se interrompem as fibras, reduzemse as áreas resistentes e se originam, na peça, solicitações secundárias de compressão normal, cisalhamento ou fendilhamento, às quais o material oferece menor resistência.

Ghavami \& Hombeeck (1981) observaram que, na maioria das vezes, o rompimento ocorria no nó, confirmando a concentração de tensões neste ponto. Constataram, ainda, que a resistência na parte basal ao longo do colmo apresentava maior carga de ruptura, devido à maior área transversal.

As características mecânicas do bambu são influenciadas sobretudo pelos fatores: espécie, idade, tipo de solo, condições climáticas, época de colheita, teor de umidade das amostras, localização das mesmas em relação ao comprimento do colmo, presença ou ausência de nós nas amostras testadas e tipo do teste aplicado (Ghavami, 1989).

Com base nos resultados obtidos das pesquisas sobre bambu durante as duas últimas décadas, em várias partes do 
mundo, incluindo-se o Brasil, foi possível criar as primeiras normas para tal utilização. Sabendo que o conhecimento das normas é importante não apenas para o uso seguro mas também para a divulgação de um material, o INBAR (1999) - International Network for Bamboo and Rattan usou os resultados dessas pesquisas mundiais e propôs normas para a determinação das propriedades físicas e mecânicas dos bambus. As normas propostas foram analisadas pelo ICBO - International Conference of Building Officials e publicadas no relatório AC 162: Acceptance Criteria for Structural Bamboo, em março de 2000 (ICBO, 2000).

Este trabalho apresenta uma análise das propriedades dos colmos inteiros do bambu da espécie Guadua angustifolia, que é parte de uma linha de pesquisa, com o fim de classificar as propriedades físicas, mecânicas e meso-estruturais dos bambus, como material do século XXI, na construção civil e nas pequenas e médias indústrias de materiais de construção.

\section{MATERIAL E MÉTODOS}

O trabalho foi desenvolvido no Laboratório de Estruturas e Materiais do Departamento de Engenharia Civil da PUC-Rio e se refere ao estudo das propriedades físicas, mecânicas e mesoestruturais do colmo do bambu da espécie Guadua angustifolia, proveniente de Guarulhos, SP, com idade média de três anos.

\section{Propriedades físicas}

O comprimento dos internós do bambu estudado foi medido de acordo com as indicações da Figura 3A. O diâmetro externo de cada internó foi determinado através de medições com o paquímetro. Para se determinar a espessura da parede ( $t$ ), perfuraram-se três furos em cada internó, com uma furadeira elétrica, com diâmetro de 5mm, (Figura 3B), fazendo-se as medições através de um medidor de espessura desenvolvido para este fim (Figura 3C).

Considerando-se $\mathrm{z}$ a distância do centro de um internó à base do colmo, L o comprimento total e p a carga de vento, o momento fletor no internó é:

$$
M=\frac{p}{2}(L-z)^{2}
$$

Se $\mathrm{M}_{\text {max }}$ é o momento fletor na base em que $\mathrm{z}=0$, na Eq. (1), pode-se exprimir adimensionalmente o momento em cada internó por:

$$
\overline{\mathrm{M}}=\frac{\mathrm{M}}{\mathrm{M}_{\max }}
$$

O módulo de resistência adimensional $\bar{Z}$ de uma seção oca cilíndrica do colmo do bambu é definido por:

$$
\overline{\mathrm{Z}}=\frac{\mathrm{Z}}{\mathrm{Z}_{\max }}
$$

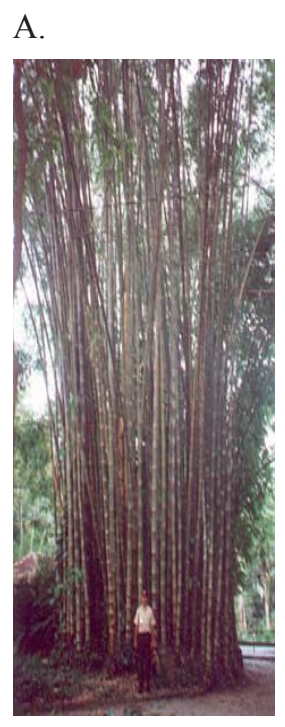

B.

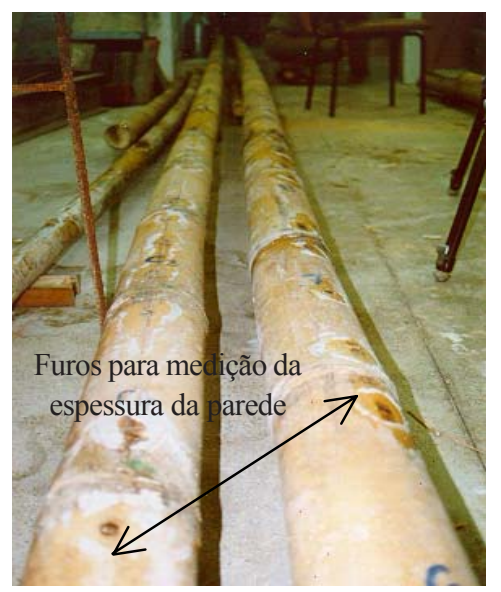

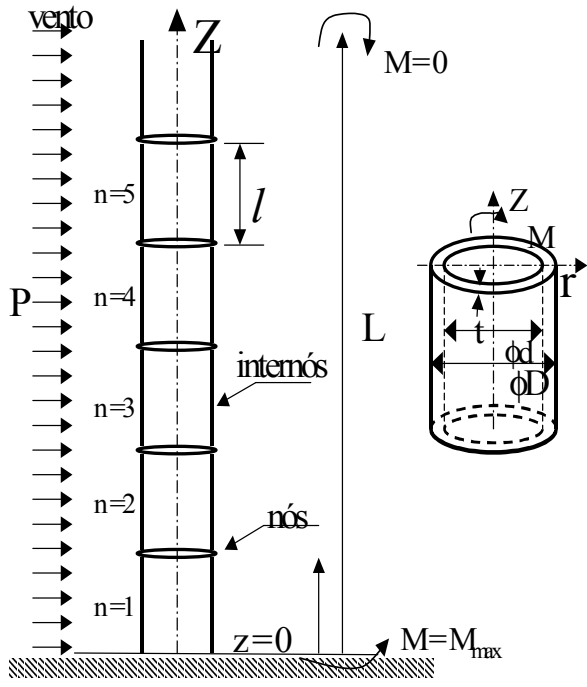

C.

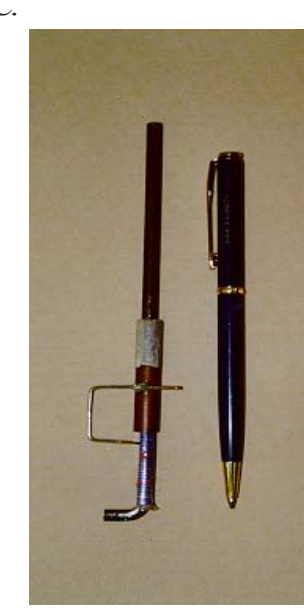

Figura 3. Configuração, posição dos furos e aparelho para medições da espessura da parede do colmo do bambu A Eixo de coordenadas, B - furos ao longo do bambu e C Medidor de espessura

sendo:

$Z$ representado pela Eq.(4) e $Z_{\max }$ o valor máximo de $Z$ na seção quando $\mathrm{z}=0$

$$
\mathrm{Z}=\frac{\pi}{32} \cdot \frac{\left[\mathrm{D}^{4}-(\mathrm{D}-2 \mathrm{t})^{4}\right]}{\mathrm{D}}
$$

A partir dos valores do momento fletor médio $(\overline{\mathrm{M}})$ e do módulo de resistência da seção $(\bar{Z})$, determina-se a tensão de flexão adimensional na superfície do colmo, devido ao momento de flexão através da Eq.(5):

$$
\overline{\sigma_{\mathrm{b}}}=\frac{\bar{M}}{\bar{Z}}
$$

donde:

$\bar{\sigma}_{\mathrm{b}}$ representa a tensão no internó qualquer $\left(\sigma_{\mathrm{b}}\right)$ dividida pela tensão máxima, que ocorre na base do colmo $\left(\sigma_{\mathrm{bmax}}\right)$ : 


$$
\bar{\sigma}_{\mathrm{b}}=\frac{\sigma_{\mathrm{b}}}{\sigma_{\mathrm{b} \max }}
$$

\section{Propriedades meso-estruturais}

Foram retiradas amostras das partes basal, central e topo do colmo do bambu Guadua angustifolia. As amostras foram lixadas (lixas n ${ }^{\circ}$ 400, 600 e 1000) e polidas (alumina, $6 \mu \mathrm{m}$ ). As imagens foram obtidas no Laboratório de Ciências dos Materiais e Metalurgia da PUC-Rio, através de uma lupa com magnificação de 6X, equipada com uma câmara fotográfica. As manipulações realizadas sobre as imagens foram realizadas no software KS400 3.0. O pré-processamento foi iniciado com o seccionamento da imagem, como mostrado na Figura 4, em que a imagem original foi dividida em quatro partes e, posteriormente, em 8 e 12, dependendo da parte do colmo analisada. Para amostras da região do topo, que tem espessura da parede em torno de $6 \mathrm{~mm}$, só foi possível dividir a imagem em até 8 fatias pois, a partir daí, as faixas são muito pequenas, dividindo os conjuntos vasculares e não possibilitando a contagem das fibras. $\mathrm{Na}$ parte basal, por sua espessura média de $12 \mathrm{~mm}$, foi possível dividir a imagem em até 12 fatias. A imagem da parte central, com espessura em torno de $8 \mathrm{~mm}$, foi dividida em até 10 fatias.

A segmentação (transformação da imagem em uma imagem binária) foi realizada de forma automática, fornecendo boa separação das imagens de interesse (fibras); após a separação nas partes desejadas, efetuou-se o processamento digital, calculando-se a porcentagem de área de fibras em cada seção.

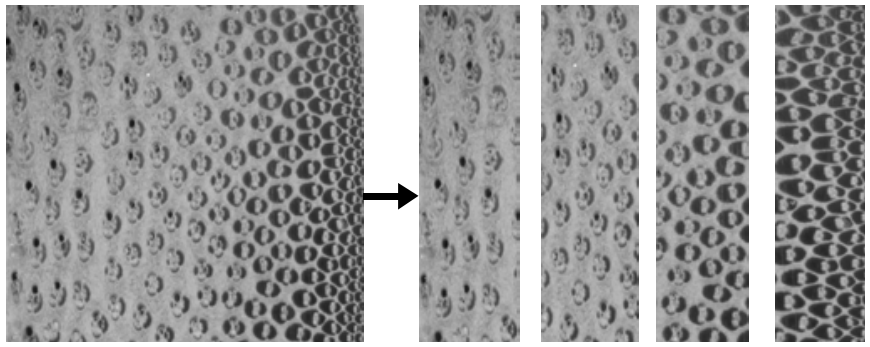

Figura 4. Seccionamento da imagem do bambu Guadua angustifolia

\section{Propriedades mecânicas}

Determinaram-se as resistências à tração, compressão e cisalhamento interlaminar das partes basais, centrais e superiores (topo) do bambu Guadua angustifolia. Para cada parte acima citada, foram ensaiados três corpos-de-prova sem nó e três com nó. Os ensaios foram realizados de acordo com as normas do INBAR (1999), utilizando-se três colmos. Para determinar a deformação do bambu nos ensaios de tração e compressão, foram colados strain gages tipo L em uma das faces do corpo-de-prova. No ensaio, o corpo-de-prova é fixado na máquina INSTRON 500, a qual é conectada ao computador e ligada ao Vischay, que é um indicador de deformação analógico manual. Para cada carga aplicada a uma velocidade de 0,05 $\mathrm{mm} \min ^{-1}$ e incremento de $10 \mathrm{kgf}$, lêem-se as deformações longitudinais e transversais às fibras do bambu.

A Figura 5 (A, B e C) apresenta as características dos corposde-prova utilizados.
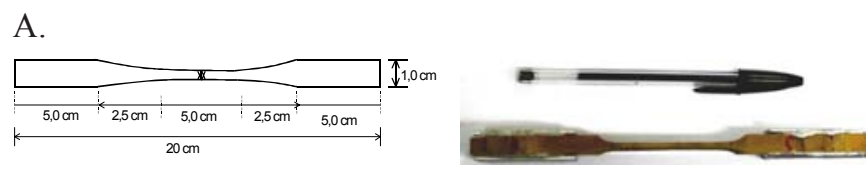

B.

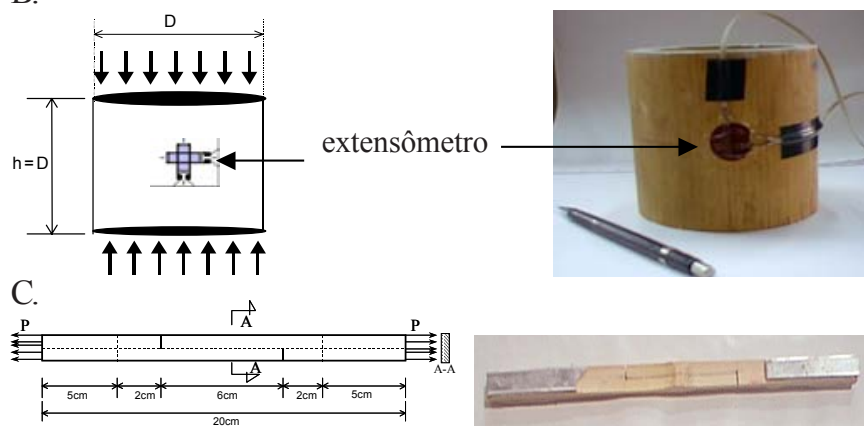

Figura 5. Características dos corpos-de-prova para ensaios de A - Tração, B - Compressão e C - cisalhamento interlaminar

\section{RESULTADOS E DISCUSSÃO}

\section{Propriedades físicas}

Os bambus têm diminuição gradual, no sentido da base para o topo, no diâmetro do colmo, na espessura da parede e no comprimento internodal. A Figura 6 mostra a variação do comprimento internodal $(l)$ do colmo inteiro em relação ao número dos internós (n) do bambu Guadua angustifolia, com a respectiva equação matemática obtida através da análise de regressão do comportamento normal da curva. Observa-se que, na parte basal, os comprimentos internodais são menores, enquanto na parte central do colmo atingem o valor máximo e, na parte superior, decrescem.

A Figura 7 (A e B) apresentam os resultados médios referentes ao diâmetro externo (D) e espessura da parede (t) em relação ao comprimento do colmo (z), com as respectivas equações matemáticas obtidas através da análise de regressão do comportamento normal da curva. Observa-se que o diâmetro externo (D) diminui da base para o topo, apresentando comportamento quase linear, com valor máximo de $101,86 \mathrm{~mm}$ na base e 31,21 mm no topo e com valor médio de 79,56 $\mathrm{mm}$. A espessura média da parede (t) é de $10,31 \mathrm{~mm}$, com valores diminuindo da base para o topo, porém apresentando grande variação ao longo do comprimento, a qual pode ser provocada pela precisão do aparelho de medição, que é de $1 \mathrm{~mm}$. Essas informações podem ser utilizadas pelos usuários de bambu,

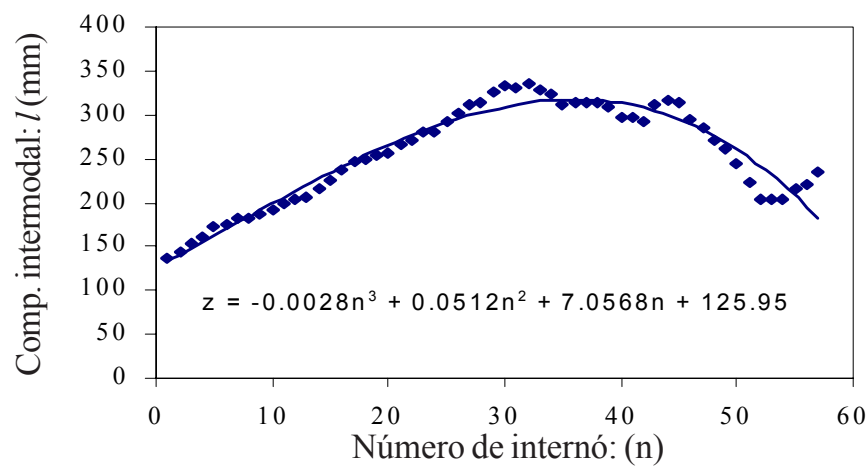

Figura 6. Comprimento internodal em função do número de internós ao longo do colmo do bambu guadua angustifolia 
A.

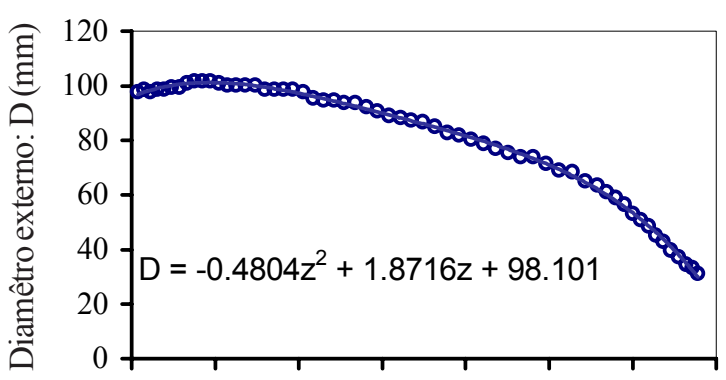

B.

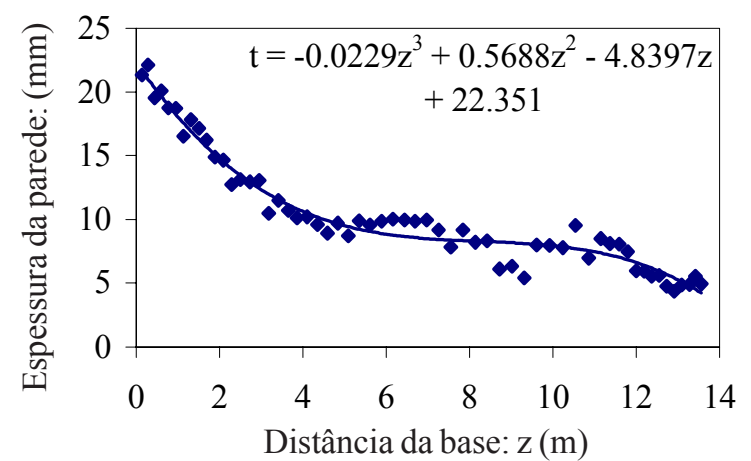

Figura 7. Diâmetro externo (A) e espessura da parede (B) ao longo comprimento do colmo

como engenheiros e arquitetos, com o objetivo de selecionar os bambus com as dimensões necessárias para seu projeto.

As curvas referentes ao momento fletor $(\bar{M})$, módulo de resistência $(\bar{Z})$ e as tensões de flexão $\left(\overline{\sigma_{\mathrm{b}}}\right)$ ao longo do colmo do bambu estudado, estão apresentadas na Figura 8. Os valores de $\bar{M}$ e $\bar{Z}$ são parâmetros importantes de resistência no dimensionamento de estruturas com bambu; $\bar{M}$ independe da espécie do bambu, pois relaciona o momento ao longo da altura total do colmo com o momento máximo; $\bar{Z}$ relaciona as características geométricas do bambu, diferenciando-as quanto à espécie e ao local cultivado; $\overline{\sigma_{\mathrm{b}}}$ representa a variação da tensão de flexão ao longo do colmo. A partir deste valor, define-se a variação da resistência ao longo do colmo do bambu à flexão. Amada (1996), ao estudar o comportamento do bambu Phyllostachys edulis Riv. (Mosó) com idade média de dois anos, no Japão, obteve valores aproximados aos do bambu Guadua angustifolia.

\section{Propriedades meso-estruturais}

Na análise da variação da fração volumétrica de fibras na espessura da parede do bambu (seção transversal), é possível se obter uma equação que a represente e observar como esta variação se relaciona com algumas propriedades dos bambus. No processamento digital de imagem (PDI), a distribuição das fibras é analisada ao longo do colmo inteiro do bambu, com amostras retiradas nos vários pontos da base, centro e topo, como mostra a Figura 9.

O gráfico da Figura 10 mostra as distribuições de fibras para as amostras analisadas. A fração volumétrica é indicada em função de uma variável adimensional $(\mathrm{X})$ que representa a razão entre a posição em que se mede a fração volumétrica na espessura (x), e a espessura total da amostra (t), ou seja x/t. A partir da análise de regressão dos pontos experimentais, obtiveram-se equações matemáticas da forma polinomial, que

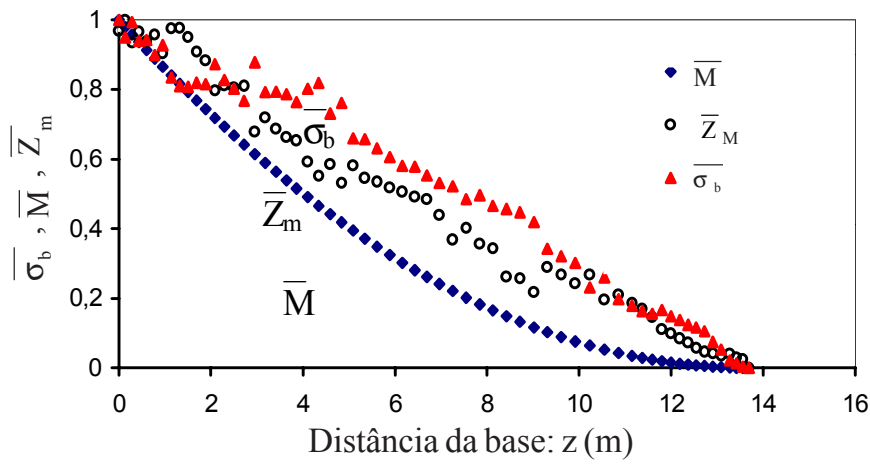

Figura 8. Módulo de resistência, momento fletor e tensão de flexão não-dimensionais ao longo do colmo do bambu Guadua angustifolia

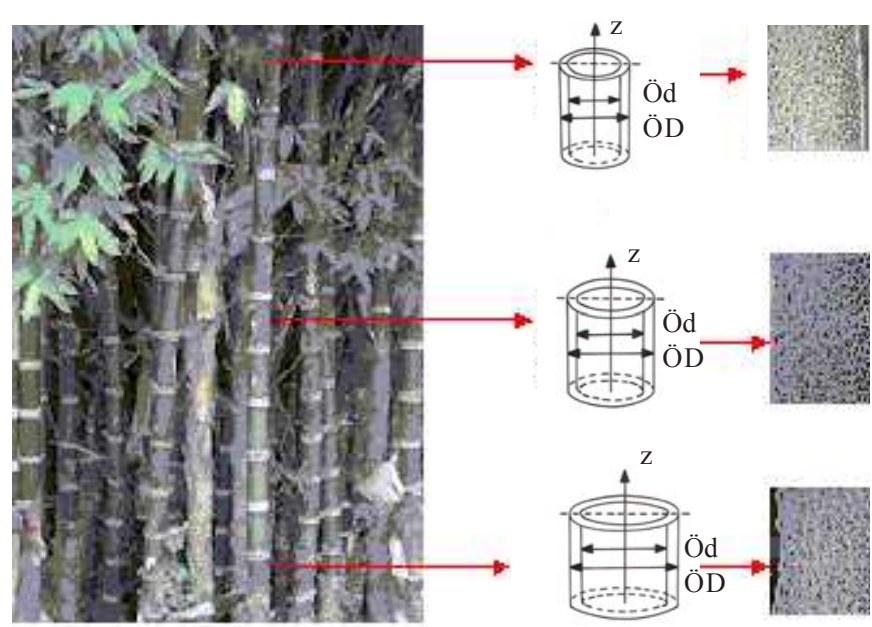

Figura 9. Indicação dos pontos de retirada das amostras do bambu Guadua angustifolia

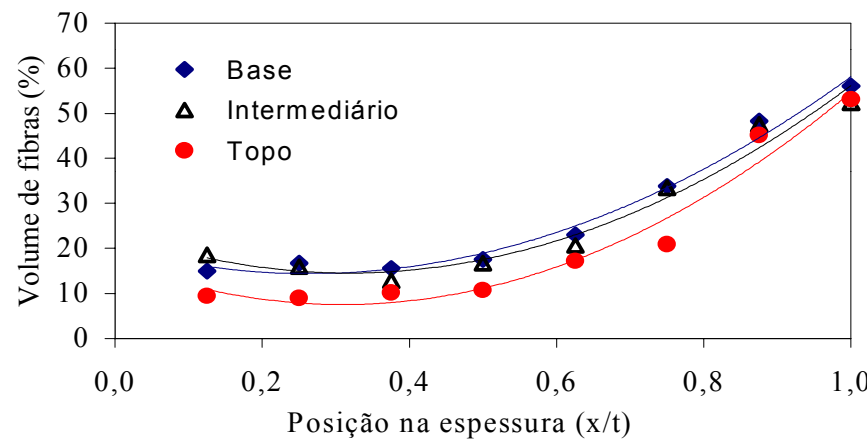

Figura 10. Comparação do volume de fibras em relação à espessura da parede entre as amostras da base, centro e topo do bambu Guadua angustifolia

permitem determinar a variação da fração volumétrica para amostras cujas imagens foram dividas em 4, 8, 10 e 12 fatias. A partir daí, optou-se pela equação relativa ao número de fatias, que resultou em menor percentual de erro. Matematicamente, quanto maior o número de divisões, melhor seria o ajuste da equação. A Tabela 1 apresenta as equações obtidas para determinar a fração volumétrica das partes basal, central e topo das imagens divididas em 8 fatias do bambu Guadua angustifolia. As equações de $3^{\circ}$ e $4^{\circ}$ graus, para as partes central e topo, foram obtidas de forma a fornecer maior precisão na determinação do volume de fibras. 
Tabela 1. Variação da fração volumétrica de fibras ao longo da espessura do bambu Guadua angustifolia nas partes da base, centro e topo

\begin{tabular}{cc}
\hline Parte do colmo & Equação \\
\hline Base & $\mathrm{V}_{\mathrm{f}}=83,1 * \mathrm{X}^{2}-40,7 * \mathrm{X}+19,1$ \\
Centro & $\mathrm{V}_{\mathrm{f}}=-101,5 * \mathrm{X}^{3}+260,7 * \mathrm{X}^{2}-138,4 * \mathrm{X}+33,4$ \\
Topo & $\mathrm{V}_{\mathrm{f}}=-412,7 * \mathrm{X}^{4}+967,8^{*} \mathrm{X}^{3}-668,3 * \mathrm{X}^{2}+171,4 * \mathrm{X}-3,9$ \\
\hline
\end{tabular}

Constata-se, na Figura 10, que a distribuição das fibras nas amostras da base e centro é mais uniforme, com a fração volumétrica variando menos que a amostra colhida no topo; isto ocorre pelo ao fato de que, da base até o centro do bambu, este, além de resistir às flexões devido às cargas de vento, deve suportar maior parte de seu peso próprio.

\section{Propriedades mecânicas}

Em seguida, apresentam-se os resultados relativos aos ensaios de resistências à tração, à compressão e ao cisalhamento interlaminar da base, centro e topo do bambu Guadua angustifolia.

Tração: Os resultados de resistência à tração, módulo de elasticidade e coeficiente de Poisson da parede do colmo do bambu Guadua angustifolia, estão apresentados na Tabela 2; nela, pode-se observar que o bambu atinge uma resistência média à tração de $86,96 \mathrm{MPa}$. No geral, a parte central apresenta maior resistência; 95,80 MPa no corpo-de-prova sem nó e 82,62 MPa no corpo-de-prova com nó. Nas regiões com nó, a resistência diminui devido à descontinuidade das fibras nesses pontos, seguindo a direção do nó. Como já ocorrido em outros ensaios, os corpos-de-prova sempre rompem no nó ou bem próximo a ele. A região do topo, sem nó, apresentou maior valor da resistência à tração, $115,84 \mathrm{MPa}$; porém no corpo-deprova com nó se obteve menor resistência, 64,26 $\mathrm{MPa}$. A resistência à tração do bambu Guadua angustifolia é 36,7\% menor que a resistência do bambu Dendrocalamus giganteus (Ghavami \& Marinho, 2001). Culzoni (1986) estudou as propriedades mecânicas do bambu da espécie Guadua superba e obteve valores de resistência à tração de 112,3 MPa e módulo de elasticidade de 8,9 GPa, no corpo-de-prova com nó; no corpo-de-prova sem nó, a autora obteve uma resistência à tração de 137,8 MPa e módulo de elasticidade de 11,2 GPa.

Tabela 2. Resistência à tração, módulo de elasticidade e coeficiente de Poisson das partes basal, centro e topo, com e sem nó, do bambu Guadua angustifolia

\begin{tabular}{cccc}
\hline $\begin{array}{c}\text { Parte do } \\
\text { bambu }\end{array}$ & $\begin{array}{c}\text { Resistência à } \\
\text { tração } \sigma_{\mathrm{t}}(\mathrm{MPa})\end{array}$ & $\begin{array}{c}\text { Módulo } \\
\text { Elasticidade-E }(\mathrm{GPa})\end{array}$ & $\begin{array}{c}\text { Coef. } \\
\text { Poisson } \mu\end{array}$ \\
\hline Base sem nó & 93,38 & 16,25 & 019 \\
Base com nó & 69,88 & 15,70 & - \\
Centro sem nó & 95,80 & 18,10 & 0,25 \\
Centro com nó & 82,62 & 11,10 & - \\
Topo sem nó & 115,84 & 18,36 & 0,33 \\
Topo com nó & 64,26 & 8,0 & - \\
\hline Valor médio & 86,96 & 14,59 & 0,26 \\
Variação & $64,26-115,84$ & $8,0-18,36$ & $0,19-0,33$ \\
\hline
\end{tabular}

No bambu em estudo, o módulo de elasticidade longitudinal às fibras variou de $11,10 \mathrm{GPa}$ a $18,36 \mathrm{GPa}$, com valor médio de $15,11 \mathrm{GPa}$ e com os maiores valores obtidos sempre nos corposde-prova sem nó. O coeficiente de Poisson médio foi de 0,26, aumentando da base para o topo.

A partir dos dados de carga e dos deslocamentos experimentais, foi possível se obter as curvas tensãodeformação do bambu, sem e com nó, apresentadas na Figura 11. No ensaio do bambu com nó, não foi possível se obter as deformações transversais em virtude de problemas com os strain gages; assim também não foi possível obter o coeficiente de Poisson. Observa-se que o comportamento da curva do bambu, com e sem nó, é praticamente linear até o ponto de ruptura. A deformação máxima longitudinal à fibra nos corpos-de-prova do bambu sem nó variou de 4000 a $6000 \mu$ strain, com maior valor na base e menor valor na parte central; já no sentido transversal às fibras, a deformação máxima variou de 800 a 2000 $\mu$ strain, com maior valor no topo e menor valor na base. Nos corpos-de-prova do bambu com nó, a deformação longitudinal às fibras variou de 4000 a $11000 \mu$ strain, com maior valor no topo e menor na base.

Compressão: Os resultados obtidos para resistência à compressão, módulo de elasticidade e coeficiente de Poisson das partes basal, central e topo, estão apresentados na Tabela 3. Observa-se que a resistência à compressão é, em geral, três vezes menor que a resistência à tração. A resistência média foi de 29,48 MPa, aumentando da base para o topo. O valor máximo da tensão ocorreu na parte do topo, sendo igual a $34,52 \mathrm{MPa}$ para o corpo-de-prova sem nó, e de 29,62 MPa com nó. Na base, este valor caiu para 25,27 MPa no corpo-de-prova com nó e 28,36 MPa sem nó. A média do módulo de elasticidade

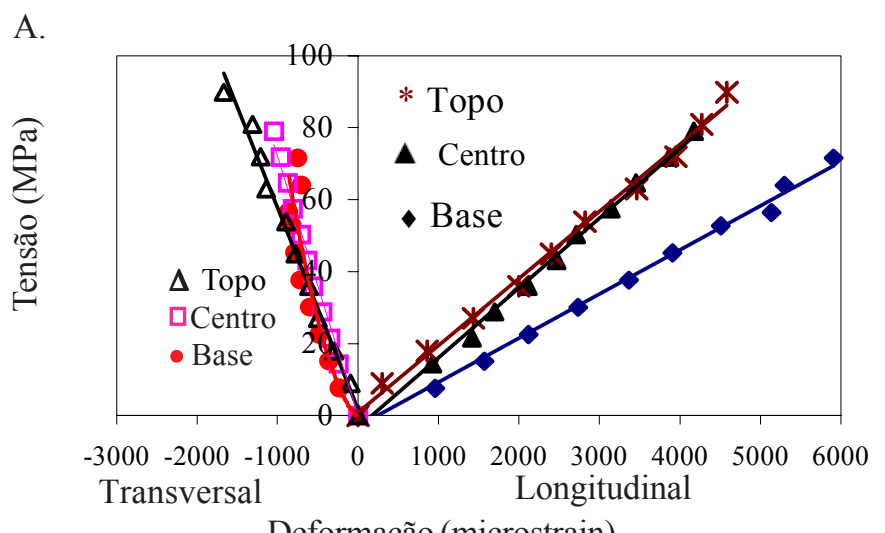

B.

Deformação (microstrain)

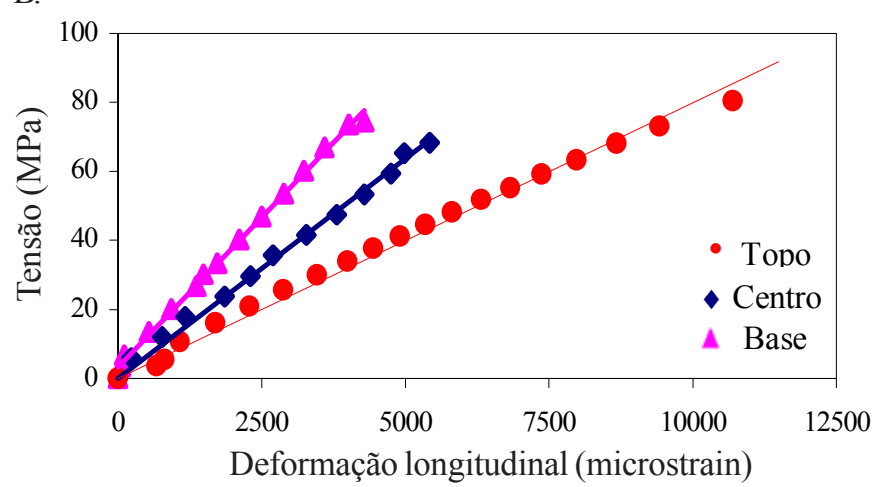

Figura 11. Tensão de tração - deformação do bambu Guadua angustifolia, com (A) e sem nó (B) 
Tabela 3. Resistência à compressão, módulo de elasticidade, coeficiente de Poisson das partes basal, central e topo, com e sem nó, do bambu Guadua angustifolia

\begin{tabular}{cccc}
$\begin{array}{c}\text { Parte do } \\
\text { bambu }\end{array}$ & $\begin{array}{c}\text { Resistência à } \\
\text { tração } \sigma_{\mathrm{t}}(\mathrm{MPa})\end{array}$ & $\begin{array}{c}\text { Módulo } \\
\text { elasticidade-E (GPa) }\end{array}$ & $\begin{array}{c}\text { Coef. } \\
\text { Poisson } \mu\end{array}$ \\
\hline Base sem nó & 28,36 & 14,65 & 0,27 \\
Base com nó & 25,27 & 9,00 & 0,56 \\
Centro sem nó & 31,77 & 12,25 & 0,36 \\
Centro com nó & 28,36 & 12,15 & 0,18 \\
Topo sem nó & 25,27 & 11,65 & 0,36 \\
Topo com nó & 31,77 & 15,80 & 0,33 \\
\hline Valor médio & 29,48 & 12,58 & 0,34 \\
Variação & $25,27-34,52$ & $9,00-15,80$ & $0,18-0,56$ \\
\hline
\end{tabular}

longitudinal às fibras foi de $12,58 \mathrm{GPa}$, variando de $9,00 \mathrm{GPa}$ na base a $15,80 \mathrm{GPa}$ na região do topo, ambos em corpos-deprova com nó. O coeficiente de Poisson médio obtido no ensaio de resistência à compressão foi de 0,34 . Culzoni (1986) determinou a resistência à compressão do bambu Guadua superba em corpos-de-prova com altura igual a duas vezes o diâmetro $(\mathrm{H}=2 * \mathrm{D})$ e obteve valores de $35,7 \mathrm{MPa}$ e módulo de elasticidade de 2,6 GPa, em corpos-de-prova com nó, e resistência de 47,8 MPa e módulo de elasticidade de 3,33 GPa, em corpos-de-prova sem nó.

A Figura 12 apresenta as curvas de tensão de compressão axial - deformação nos sentidos longitudinal e transversal às fibras do bambu, com e sem nó, e nas partes da base, centro e topo. Observa-se que, até próximo à ruptura, a curva apresenta comportamento quase linear. Em alguns ensaios percebe-se uma plastificação do material. Foi colado, nas amostras, strain gages do tipo roseta em L, com o objetivo de medir as deformações longitudinais e transversais às fibras. Na maioria dos ensaios da parte central verificou-se que o corpo de prova sem nó, não sofre, inicialmente, deformação no sentido transversal às fibras, o que se deve, provavelmente, ao confinamento provocado pelas placas da máquina de ensaio, já que o corpode-prova tem altura igual ao diâmetro. No corpo-de-prova com nó ocorreu apenas deformação longitudinal às fibras, devido a presença do nó inibir o achatamento e, conseqüentemente, a deformação no sentido transversal às fibras. As deformações longitudinais máximas, para os bambus sem e com nó, variaram de 2500-5000 $\mu$ strain e 2500-8000 $\mu$ strain, respectivamente, com as maiores deformações na parte central sem nó e topo com nó. As deformações máximas transversais às fibras apresentaram valores médios de $1500 \mu$ strain. No início do ensaio de compressão, o strain gage, colocado no sentido transversal às fibras, sofreu uma deformação negativa, significando um encurtamento; com o aumento da carga aplicada, as fibras foram tracionadas, tornando a deformação transversal positiva.

Cisalhamento: Os resultados médios da resistência ao cisalhamento interlaminar para os corpos-de-prova localizados na base, centro e topo do bambu Guadua angustifolia, são apresentados na Tabela 4. Os valores foram obtidos a partir da média de três ensaios. Nesta, observa-se que os valores aumentam da base para o topo, sendo que no topo a resistência ao cisalhamento foi de 2,42 MPa para o corpo-de-prova sem nó e 2,11 MPa para o corpo-de-prova com nó. Na base, esses
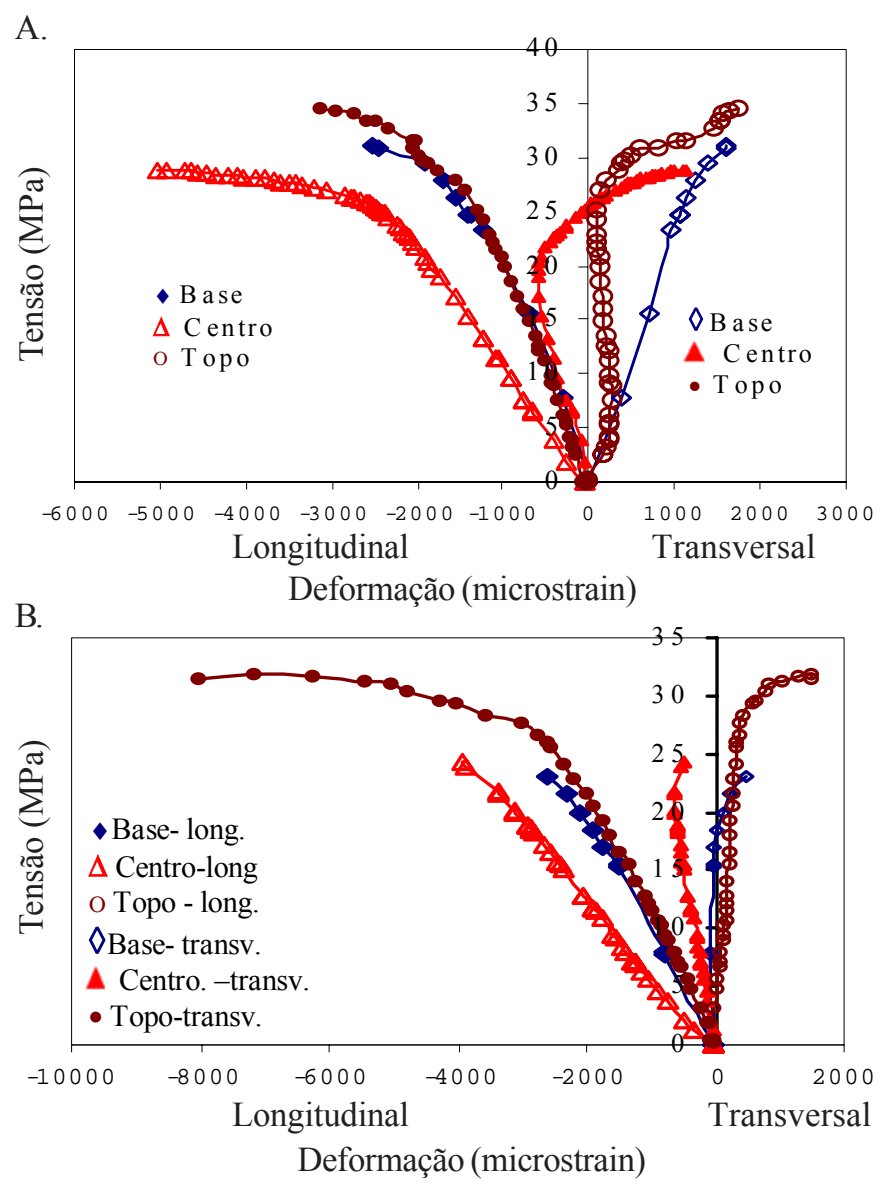

Figura 12. Tensão de compressão-deformação do bambu com (A) e sem nó (B)

Tabela 4. Resistência ao cisalhamento interlaminar do bambu Guadua angustifolia

\begin{tabular}{lcc}
\hline \multicolumn{2}{c}{ Partes do colmo } & Tensão de cisalhamento $\tau(\mathrm{MPa})$ \\
\hline \multirow{2}{*}{ Base } & Com nó & 1,668 \\
& Sem nó & 2,198 \\
\hline \multirow{2}{*}{ Centro } & Com nó & 1,433 \\
& Sem nó & 2,272 \\
\hline \multirow{2}{*}{ Topo } & Com nó & 2,113 \\
& Sem nó & 2,421 \\
\hline \multicolumn{2}{c}{ Valor médio } & 2,017 \\
\hline
\end{tabular}

valores foram 2,20 MPa sem nó e 1,67 MPa com nó, respectivamente. Observa-se que, nos corpos-de-prova sem nó, a resistência é maior e se mantém quase uniforme nas três partes do comprimento do colmo; já nas partes com nó, a resistência é menor e os valores variam muito.

A resistência ao cisalhamento do bambu Guadua angustifolia é inferior à do bambu Dendrocalamus giganteus. Ghavami \& Marinho (2001) obtiveram valores médios de 3,56 $\mathrm{MPa}$ e 3,37 MPa para corpos-de-prova com e sem nó, respectivamente. Moreira (1991) obteve uma tensão de cisalhamento média de 7,0 MPa para o bambu Dendrocalamus giganteus, enquanto Ghavami \& Souza (2000) obtiveram valores de tensão de cisalhamento de 3,08 e 3,12 MPa para corpos-de-prova com dois e três cortes, respectivamente, e para o mesmo bambu estudado. 


\section{CONCLUSÕES}

1. Os bambus têm diminuição gradual, no sentido da base para o topo, no diâmetro do colmo, na espessura da parede e no comprimento internodal.

2. O módulo de resistência, que é função do diâmetro e da espessura da parede, varia ao longo do colmo.

3. A aplicação do processamento digital de imagens, para obtenção da distribuição volumétrica das fibras ao longo da espessura da parede, foi feita de forma simples e forneceu resultados que podem ser considerados satisfatórios, uma vez que não se tem outras fontes de comparação na literatura nem, tampouco, resultados "analógicos" das grandezas medidas neste trabalho para a espécie de bambu estudada.

4. Os ensaios experimentais realizados para obtenção das características mecânicas do bambu Guadua angustifolia demonstraram que ele resiste mais aos esforços de tração que aos de compressão, com diferença de valores superior a $50 \%$ em todas as partes analisadas.

5. As curvas de tensão-deformação obtidas nos ensaios de tração e compressão indicam que o bambu Guadua angustifolia apresenta comportamento quase linear, até o ponto de ruptura.

6. A resistência média à tração do bambu Guadua angustifolia foi de $86,96 \mathrm{MPa}$, apresentando maiores valores na parte central, ou seja, 95,80 MPa no corpo-de-prova sem nó e de 82,61 MPa no corpo-de-prova com nó. O módulo de elasticidade médio foi de $15,11 \mathrm{GPa}$ no sentido longitudinal às fibras. O coeficiente de Poisson médio no ensaio de tração foi de 0,26 , com os valores aumentando da base para o topo.

7. A resistência à compressão média foi de $29,48 \mathrm{MPa}$, com valor máximo de 29,62 MPa e 34,52 MPa na parte superior, com e sem nó, respectivamente. De modo geral, a resistência à compressão foi pouco influenciada pela presença do nó. $\mathrm{O}$ módulo de elasticidade médio no ensaio de compressão foi de $12,58 \mathrm{GPa}$, no sentido longitudinal às fibras.

8. A resistência média ao cisalhamento interlaminar foi de 2,02 MPa, com os valores máximos na parte superior do colmo. A resistência diminuiu do topo para a parte basal do colmo.

9. De acordo com os resultados obtidos para o Guadua angustifolia e os comparados pelo grupo de pesquisa da PUCRio para o Dendrocalamus giganteus, as resistências do bambu Guadua angustifolia são menores que as do Dendrocalamus giganteus, verificando-se que a diferença é de 43,8\% na resistência à tração, $41,6 \%$ na resistência à compressão e $60 \%$ na resistência ao cisalhamento.

\section{AGRADECIMENTOS}

Os autores agradecem aos colegas que contribuíram para a realização dos ensaios, especialmente ao Professor Sidnei Paciornik, pela valiosa colaboração na análise da mesoestrutura do bambu; aos alunos Diogo Rodrigues Mota, Celso Luiz de Oliveira Junior, Sergio Luís Vanderley e Eliane Fernandes Côrtes Pires pela participação nas pesquisas. Agradecem também à FAPERJ, CAPES e CNPq, pelo apoio financeiro.

\section{LITERATURA CITADA}

Amada, S.; Munekata, T.; Nagase, Y.; Ichikawa Y.; Kirigai, A.; Zhifei, Y. The mechanical structures of bamboos in viewpoint of functionally gradient and composite materials. Journal of Composite Materials, Thousand Oaks, v.30, n.7, p.801-819, 1996.

Culzoni, R.A.M. Caraterísticas dos bambus e sua utilização como material alternativo no concreto. Rio de Janeiro: PUCRio, 1986. 134 p. Dissertação Mestrado

Ghavami, K. Application of bamboo as a low-cost energy material in civil engineering. In: Symposium Materials for Low Income Housing, 3, 1989, Mexico City. Symposium...Mexico: CIB/RILEM, 1989.p.526-536

Ghavami, K. Bambu: um material alternativo na engenharia. Revista do Instituto de Engenharia, São Paulo, n.492, p.23-27, 1992.

Ghavami, K. Cement composites reinforced with bamboo and vegetable fibres. In: International Conference on Concrete and Development, 1, 2001, Tehran. Proceedings... Tehran: Building and Housing Research Centre, 2001, p.445-461, v.2.

Ghavami, K.; Culzoni, R. A.M. Utilização do bambu como material em habitação de baixo custo. In: International Symposium on Transfer and Production of Housing Technology in Research and Pratice HABITEC 87, 1987, São Paulo. Proceedings...São Paulo: IPT and CIB, 1987. p.181-188.

Ghavami, K.; Fang, H.Y. (ed.) Low cost and energy saving construction materials, Lehigh: ENVO Publishing Company, v.1, 1984.

Ghavami, K.; Hombeeck, R.V. Application of bamboo as a construction material. Part I- Mechanical properties \& water - repellent treatment of bamboo, Part II- Bamboo reinforced concrete beams. In: Latin American Symposium on Rational Organization of Building Applied to Low Cost Housing, 1981, São Paulo. Proceedings...São Paulo: IPT/CIB, 1981.p. 49-66, v.1.

Ghavami, K.; Marinho, A.B. Determinação das propriedades dos bambus das espécies: Mosó, Matake, Guadua angustifolia, Guadua tagoara e Dendrocalamus giganteus para utilização na engenharia. 1. ed. Rio de Janeiro: RMNC do Departamento de Engenharia Civil da PUC-Rio, 2001.53p.

Ghavami, K.; Rodrigues, C.S. Engineering materials and components with plants. In: CIB-Symposium, Construction \& Environment, 2000, São Paulo. Proceedings...São Paulo: Global Seven Editor, 2000. CD Rom

Ghavami, K.; Souza, M.V. de. Propriedades mecânicas do bambu. Rio de Janeiro: Relatório Interno apresentado ao PIBIC, PUCRio. Ago., 2000.

ICBO- Ac 162: Acceptance criteria for structural bamboo: ICBO Evaluation Service Ltd. California, 2000.

INBAR- The International Network on Bamboo and Rattan. In: International model building code for bamboo. Jan., 1999.

Liese, W. Anatomy of bamboo. In: Bamboo research in Asia, 1980, Ottawa. Proceedings... Ottawa: IDRC, 1980.p. 165-172.

Liese, W. The anatomy of bamboo culms. Technical Report, International Network for Bamboo and Rattan, Beijing, Eindhoven, New Delhi, 1998, 208p.

Moreira, L.E. Desenvolvimento de estruturas treliçadas espaciais de bambu. Rio de Janeiro: PUC-Rio, 1991. 172p. Dissertação Mestrado 